\title{
Kent Planlamada Yeni Bir Yöntem Önerisi: Kentsel Dirençlilik Endeksi
}

\author{
Şeyma Elif DíNCER ${ }^{1}$, Özge YALÇINER ERCOŞKUN ${ }^{1}$
}

\section{Öz}

Son yıllardaki iklim değişikliği ve çevre verileri, doğal afetler, kaynakların tüketimiyle ilgili belgeler, kentlerin sürdürülebilirliğe aykırı olduğunu ortaya koymakta ve dünyayı ekolojik eşiklerin üstüne çıkarmaktadır. İklim değişikliğinin kentlere getirdiği riskler giderek artmakta, kentte yaşayanlara ve kentsel altyapılara yönelik tehditler oluşturmaktadır. Ekolojik boyuta ek olarak, afetler, sosyal olaylar, savaşlar, terör, salgın hastalıklar gibi olaylarla kentler hasar görebilir konuma gelmektedir. Bu karmaşık, belirsiz ve sürekli değişen riskler karşısında kentleri güvence altına almak, kentsel ekosistemleri, türleri ve bunların sağladığı hizmetleri korumak için yeni politikalar ortaya koymak gerekmektedir. İnsanların çevresel değişimin temel sebeplerinden biri olduğu göz önüne alındığında, sadece daha yaşanabilir, sürdürülebilir ve dirençli kentler yaratmak için değil, aynı zamanda insanoğlunun tüm gezegen üzerindeki çevresel ve sosyal etkilerini azaltmak için kent planlamada yeni paradigmalar getirmek gereklidir. Bununla birlikte, kentsel alanlar için dirençliliğin (urban resilience) ne anlama geldiğine ve kent planlamada dirençliliğin nasıl sağlanabileceğine dair bir fikir birliği yoktur. Bu çalışmada kentleri ve kentte yaşayanları iklim değişikliğinin etkilerine ve olası risklere hazırlamak adına kentsel dirençlilik konusunda farklı yaklaşımlar, teori ve pratik arasındaki bağın oluşturulması için yapılması gerekenler üzerinde durulmuştur. Dirençlilik konusunun nicel yöntemlerle planlama süreçlerine dahil edilmesi gerekliliği ve bu yöntemlerin nasıl oluşturulacağı açıklanmıştır. Bu konuda ölçüm ve endeks oluşturma yolundaki göstergeler araştırılıp yeni göstergeler önerilmiş; ne tür endeksler ve formüller çıkarabileceği tartışılmıştır.

Anahtar Kelimeler : Kentsel Dirençlilik, Hasar Görebilirlik, İklim Değişikliği, Afet ve Risk Yönetimi, Endeks Çalışmaları

\section{A New Method Proposal in Urban Planning: Urban Resilience Index}

\begin{abstract}
The data about climate change, environment, natural disasters, and the documents on the consumption of resources reveal that cities are against sustainability and bring the world above ecological thresholds in recent years. Risks caused by climate change are increasing, creating threats to residents and urban infrastructures. In addition to the ecological dimension, the city residents and systems become vulnerable to events such as disasters, social events, wars, terror and epidemics. In the face of these complex, uncertain and ever-changing risks, it is necessary to introduce new policies to make cities safe and protect urban ecosystems. Considering that people are the main reason of environmental change, it is a priority to introduce new paradigms in urban planning. It is necessary to create more livable, sustainable
\end{abstract}

\footnotetext{
${ }^{1}$ Gazi Üniversitesi, Mimarlık Fakültesi, Şehir ve Bölge Planlama Bölümü, ANKARA-TÜRKIYE

*ilgili yazar / Corresponding author: seymaelifsirin@gmail.com

Gönderim Tarihi / Received Date: 13.12.2020

Kabul Tarihi / Accepted Date: 01.11.2021
} 
and resilient cities and also to reduce environmental and social impacts of climate change on the entire planet. However, there is no consensus on resilience concept for urban areas and how resilience can be provided in urban planning. In this study, in order to prepare cities for all kind of changes, things should be done to create the link between theory and practice, the necessity of resilience in planning processes with quantitative methods and creation of these methods are explained. In this regard, the indicators for measurement and index formulation were investigated, and what kind of indices and formulas could be produced were discussed.

Keywords: Urban Resilience, Vulnerability, Climate Change, Disaster and Risk Managment, Index Studies

\section{Giriş}

Kentleşme arazi kullanım değişikliğinin ve küresel çevresel bozulmanın önemli bir nedenidir. Dünya çapında hızlanan kentleşmeyle, yirmi birinci yüzyıl için daha sürdürülebilir, dayanıklı ve yaşanabilir kentleri planlamak için kentsel ekosistemleri, türleri ve bunların sağladığı hizmetleri korumak için yeni politikalar ortaya koymak zorunludur.

Yakın tarihli bir dizi çalışma (örn: Davoudi, 2009; Fleischhauer, 2008; Gleeson, 2008; IPCC, 2007), mekânsal planlamanın, kentlerin mekânsal konfigürasyonu yoluyla iklim değişikliğiyle başa çıkmak için kentsel direnci artırmada önemli bir rol oynayabileceğini belirtmektedir. Kentsel planlama iklim değişikliğinin olumsuz etkilerine adapte olmanın ve iklim değişikliğine neden olan emisyonların (örn. $\mathrm{CO}_{2}$ emisyonu) azaltılması için bir araç olarak tanımlanmıştır. Politika belgeleri, bu terimi, uyum veya emisyon stratejilerini ya da bazen her ikisini de ifade etmek için giderek daha fazla kullanmaktadır (Davoudi ve diğ.,2012).Küresel iklim olayları ve insanların ve toplulukların karşılaştığı riskleri ve etkisini azaltmak ve vatandaşlarının emniyet ve refah düzeyini arttırmak için kentler ve toplumlar daha esnek ve tehditlerle baş etmeye hazır olmalıdırlar. Aksi takdirde kentte yaşayanlar sürekli tehdit altında yaşayacak ve giderek daha fazla riske açık hale gelecektir (UNISDR, 2010).İklim değişikliği, mekânsal planlamada gittikçe önem kazanan bir konudur. İklim değişikliği dirençlilik açısından değerlendirildiğinde salt hasar veren olaylarla(fırtınalar, sıcak hava dalgaları gibi) değil aynı zamanda etkisi gün geçtikçe hissedilen (deniz seviyesindeki yükselmeler ve ortalama küresel sıcaklıklar) eğilimlerle daha büyük hasarlara neden olabileceği vurgulanmaktadır (Wardekker, de Jong, Knoop ve van der Sluijs, 2010).

Kentsel iklim değişikliği ve kentlerin iklim değişikliğine karşı uyumu konusunda, dirençliliğe dayanan bir yaklaşım, uygulayıcıları yenilikleri değerlendirmeye, stres ve şoklardan kurtulmaya yardımcı olabilecek değişiklikleri öngörülebilir hale getirmektedir. Stratejik bir yaklaşım olarak dirençlilik geliştirme, dinamik ve yüksek belirsizlikle karşı karşıya olan karmaşık sosyal ekolojik sistemler için geleneksel sistem yönetimi üzerine birçok avantaja sahiptir (Walker ve diğ., 2006).

Güncel değişikliklerin kapsamı ve hızı, plancıların esnek kentleri şekillendirmek için zorlayıcı vizyonları ve entegre tasarım önlemlerini tanımlamalarını gerektirmektedir. Plancılar enerji ve ulaşımdan suya ve yeşil altyapıya kadar bu sistemleri ekolojik ayak izini küçültmek, esnek kent biçimini yapılandırmak ve kentlerimizi iklim değişikliğine uyarlamak için şekillendirmelidir. Kentlerin geleceğinin kentleşme, iklim değişikliği etkileri ve afet tehditleriyle ilgili zorluklarla dolu olduğu görülmektedir (Eraydın, 2013). Diğer faktörler aynı zamanda kentlerin yaşlanan altyapılar, kötüleşen yaşam koşulları, kaynak tükenmesi, sosyo-politik çatışma, yanlış planlama kararları gibi uzun vadeli savunmasızlıklarını arttırmaktadır. Bu faktörler, esas olarak, kronik olmaları ve yavaş başlangıçları nedeniyle sıklıkla göz ardı edilmektedir. Mevcut araştırmaların çoğunda doğal afetleri önleme açısından dirençlilik ifade edilebilirken (Chelleri, 
2012; Godschalk, 2003) insan kaynaklı kronik faktörler üzerinden tanımlanan bir dirençlilik ifadesi yoktur.

Kentsel dirençlilik konusunda yayınların ve politika girişimlerinin hızlı bir şekilde büyümesine rağmen, konseptin tanımlanması veya uygulama süreçleri üzerinde fikir birliği bulunmamaktadır. Bu çalışmada kentleri iklim değişikliği, doğal afetler ve beklenmedik risklere(salgın hastalık, terör gibi) karşı kentsel dirençliliği ölçmek, planlamaya ve politikaya yansıtmanın yollarını aramak, kentlere ve planlamaya özgün bir yaklaşıma duyulan intiyacın vurgulanması, dirençlilik teorisi ve pratiği arasındaki uçurumu kapatmak hedeflenmektedir.

\subsection{Dirençlilik Kavramı}

Resilience kavramı Türkçe' ye farklı şekillerde tercüme edilmiştir. Dirençlilik, dayanıklılık ve esneklik olarak kullanılmaktadır. Bu çalışmada iklim değişikliği, afet ve risklerin etkilerini atlatıp ileriye dönük olarak dayanma kapasitesine bakılacağı için kapsamında başlangıçtaki yapısından farklı bir konumda olacağı düşünülerek için dirençlilik kullanılmıştır. Dirençlilik, günlük söylemlerde sürdürülebilirlik kelimesinin yerini alan, sürdürülebilirlikle ilgili bilimleri destekleyen temel bir kavram haline gelmiştir. Dirençlilik yeni sürdürülebilirlik değildir ancak iki kavram arasında önemli örtüşmeler bulunmakta, sürdürülebilirliği sağlamak için gösterilen çabalar dirençlilik açısından olumlu sonuçlar getirmektedir (Ercoşkun, 2012) Son yıllarda dirençlilik kavramı ve temelleri çeşitli ekollerde ve karar alma çevrelerinde geniş bir alanda kendine yer bulmaktadır (Coaffee, 2013). Kentin sosyal ve fiziksel bileşenleriyle ilişkilendirilen dirençlilik (Coaffee ve Bosher, 2008); ekolojik, afet ve risk azaltımı, sosyal, kurumsal ve ekonomik olarak dört ana başlık altında incelenmiştir. Bu kavram 1970'li yılların sonlarında ekolojik değişim ve dengelerin anlaşılmasında kullanılmaktadır. 1990'ların ortalarında afet risk azaltma üzerine yapılan çalışmalarda da yer verilmeye başlanmıştır. 2000'li yıllardan sonra iklim değişikliğine uyum süreçleriyle birlikte kullanılmakta olan bir kavramdır. Bu kavramın literatürdeki tanım ve özellikleri Tablo 1 'de listelenmiştir.

Tablo 1.Dirençlilik Tanım ve Özellikleri

\begin{tabular}{|c|c|c|}
\hline $\begin{array}{l}\text { DiRENÇLILIKK } \\
\text { ÖZELLİKLERİ }\end{array}$ & DIRENÇLILIKK TANIMI & LİTERATÜR \\
\hline SAĞLAMLIK & $\begin{array}{c}\text { Elemanların sistemlerin ya da diğer analiz } \\
\text { ünitelerinin fonksiyon kaybı olmadan ve bozulma } \\
\text { yaşanmadan verilen şiddet seviyesine } \\
\text { dayanabilme kabiliyeti }\end{array}$ & $\begin{array}{l}\text { Linnenluecke, Griffiths, } 2010 \text {, } \\
\text { Wardekker ve diğ 2010, } \\
\text { Bruneau ve diğ., } 2003\end{array}$ \\
\hline ÇABUKLUK-HIZ & $\begin{array}{c}\text { Önceliklerini yerine getirmek ve zamanında } \\
\text { hedeflere ulaşma kapasitesi }\end{array}$ & $\begin{array}{l}\text { Walker ve Salt,2006, Bruneau } \\
\text { ve diğ., 2003, ARUP,2014 }\end{array}$ \\
\hline ÇEŞITLİLIKK & $\begin{array}{c}\text { hizmetlerin dağıtılmış kaynakları ve çok } \\
\text { fonksiyonlu ekipmanları kullanarak çeşitli yollarla } \\
\text { sağlanabileceği anlamına gelir. Bir yol başarısız } \\
\text { olursa, başka bir yol aynı hizmeti elde etmek için } \\
\text { kullanılabilir. }\end{array}$ & $\begin{array}{c}\text { Walker ve Salt,2006, Bruneau } \\
\text { ve diğ., 2003,Fleischhauer, } \\
2008\end{array}$ \\
\hline $\begin{array}{l}\text { YEDEKLEME- } \\
\text { FAZLALIK }\end{array}$ & $\begin{array}{c}\text { Var olan elemanları, sistemleri ve diğer analiz } \\
\text { ünitelerini yerine koyma derecesi, yani } \\
\text { parçalanması, bozulması ya da işlev kaybı } \\
\text { durumunda fonksiyonel gereksinimlerini } \\
\text { karşılayabilme kapasitesine sahip olma, sistem } \\
\text { özelliklerinin amaca ulaşmak için alternatiflere izin } \\
\text { vermesi }\end{array}$ & $\begin{array}{c}\text { Bruneau ve diğ, 2003, } \\
\text { Godschalk, 2003,(Ahern, 2011; } \\
\text { Brown et al., 2012; } \\
\text { Campanella, 2006; Desouza \& } \\
\text { Flanery, 2013; Godschalk, } \\
\text { 2003; Wardekker, de Jong, } \\
\text { Knoop, \& van der Sluijs, 2010; } \\
\text { Wilkinson, 2011) }\end{array}$ \\
\hline ENTEGRASYON & $\begin{array}{l}\text { Planların ve eylemlerin birden fazla departman ve } \\
\text { harici organizasyonlara entegre olması }\end{array}$ & Coaffee, 2013; Eraydın, 2013 \\
\hline BAŞA ÇIKMA & $\begin{array}{l}\text { Problem tanımlama kapasitesi, öncelikleri } \\
\text { gözeterek birtakım eleman, sistem veya diğer } \\
\text { analiz ünitesini bozucu tehdit bulunduğunda } \\
\text { kaynaklarını harekete geçiren koşullar - öncelikli } \\
\text { hedeflere ulaşmak için insan kaynaklarını ve }\end{array}$ & Bruneau ve diğ., 2003 \\
\hline
\end{tabular}




\begin{tabular}{|c|c|c|}
\hline & $\begin{array}{c}\text { materyali (maddi, fiziksel, teknolojik, bilgi) } \\
\text { kullanma kabiliyetinin oluşması, gerekli } \\
\text { kaynakların seferber kapasitesi }\end{array}$ & \\
\hline DUYARLILIK & $\begin{array}{c}\text { Algılayıcı altyapı sistemleri, performans verilerinin } \\
\text { şeffaflığını ve işlevselliği korumak için hızlı bir } \\
\text { ayar yapılmasını sağlayan otomatik izleme, kısa } \\
\text { geri besleme döngüleri ve kontrolleri birden çok } \\
\text { noktada birleştirir. }\end{array}$ & ARUP,2014 \\
\hline KOORDINASYON & $\begin{array}{c}\text { Sistemlerin koordinasyonu bilginin paylaşıldığı, } \\
\text { planlamanın işbirlikçi ve stratejik olması karşılıklı } \\
\text { yarar sağlamak için entegre edilmesidir. }\end{array}$ & $\begin{array}{l}\text { ARUP,2014, Van den Brink ve } \\
\text { diğ, 2011, Gupta ve diğ, } 2010\end{array}$ \\
\hline ETKINLİK & $\begin{array}{c}\text { Karar alma süreçlerine herkesin katılmasına fırsat } \\
\text { vermek ve sosyal ve teknik altyapıya erişimin } \\
\text { sağlanmasıdır. }\end{array}$ & Eraydın, 2013 \\
\hline $\begin{array}{l}\text { ADAPTASYON } \\
\text { KAPASITESI }\end{array}$ & $\begin{array}{l}\text { Tüm sakinlerin iklim değişikliğine uyum sağlama } \\
\text { kapasitesinin sağlanması }\end{array}$ & Eraydın, 2013 \\
\hline DİRENÇLİLİK & $\begin{array}{l}\text { Operasyonlarını ve planlarını gerektiğinde } \\
\text { değiştirmek için açık ve esnek hale getirmek }\end{array}$ & Bahadur ve diğ. , 2010 \\
\hline ÇEVRE DUYARLI & Doğal sistemleri ve yapıları korumak & Brown ve diğ.,2012 \\
\hline EŞITLİK & Eylemlerin ve etkilerin adil olmasını sağlamak & $\begin{array}{l}\text { Bahadur, Ibrahim, \& Tanner, } \\
\text { 2010; Godschalk, } 2003\end{array}$ \\
\hline $\begin{array}{l}\text { TEKRARLAYAN } \\
\text { SÜREÇ }\end{array}$ & $\begin{array}{l}\text { Geri bildirimlerin ve öğrenilen derslerin } \\
\text { gelecekteki faaliyetleri bilgilendirmek için sürekli } \\
\text { olarak kullanıldığı bir süreç oluşturma }\end{array}$ & Brown ve diğ.,2012 \\
\hline
\end{tabular}

Sonuç olarak dirençlilik terimi bir sistemin ve toplumun karşılaştığı tehlike ve afetlere karşı dayanması, o tehlikeleri atlatması, uyum sağlaması, afetlerin etkilerinin etkin ve zamanında onarımı, aynı zamanda mevcut yapısını ve fonksiyonunu koruması ve onarımını sağlamasıdır (UNISDR, 2009). Dirençlilik teriminin yukarıda tanımlanan çeşitli özelliklerinin yanında kentlerin karşılaştığı sorunların üstesinden gelme ve kentsel sistemlerin bütünlüğünü korumaya yönelik bir kavramdır.

\subsection{Kentsel Dirençlilik}

Dirençliliğe ilgi, kentsel planlama hakkındaki düşünce ve politika söylemlerine yansımıştır. Kent planlamasına karşı dirençlilik yaklaşımı geleceğin büyük bir sürpriz unsuru içereceğini ve kentsel sistemlerin ani ve beklenmedik değişikliklere uyum sağlayacak şekilde tasarlanması ve işletilmesi gerektiğini varsayar. Bu yaklaşım, kent plancıları için önemlidir, çünkü belirsiz bir gelecek karşısında uzun vadeli planlar yapmaları gerekir.

Dünyada kentsel dirençliliği sağlamak için oluşturulan yayınlar incelendiğinde; 2009 yılında 15 Asya şehri için iklim ve afet bağlamında doğal, fiziksel, sosyal, ekonomik ve kurumsal tabanlı dirençlilik göstergeleri belirlenmiştir. Bu veriler, kentler için bir dirençlilik haritası geliştirmek ve daha sonra genel bir İklim Afet Dirençlilik Endeksi'ne derlemek için kullanılmıştır (Shaw, 2009). 2009 yılında Asian Cities Climate Change Resilience Network (ACCCRN) belgesinde yayınlanmıştır. Bu çalışma kentlere ve vatandaşlarına iklim değişikliğinin kentsel alanlara getirdiği zorlukları belirleyen ve bunlara cevap veren esnek ve dinamik sistemler ve kurumlar inşa etmelerinde yardımcı olmaktadır. Asya'daki 10 kentde pilot olarak uygulanan kapsamlı bir araştırma ve kentsel iklim dirençliliği eylem programı olan ACCCRN, dış uzmanlar, ulusal ortaklar, yerel yönetimler ve diğer kuruluşlar arasındaki işbirliği sayesinde her şehrin iklim değişikliğinin karmaşıklığına karşı koymasını ve özgül sorunlarını çözmek için yerel kapasiteyi geliştirmesini sağlamakta ve ACCCRN programının şu andaki evresi, ortak kentlere dirençlilik stratejileri ve ilgili uygulama önerileri geliştirmeye yardımcı olmaktadır( Opitz-Stapleton ve diğ.,2009).

Uluslararası kuruluşlar kentsel dirençlllik konusunda gerekli yönlendirmelerini içeren planlar ve programlar geliştirmiştir. Birleşmiş Milletler Afet Azaltma Stratejisi, 2010 yılında "Esnek 
Kent Oluşturma" başlıklı yeni bir kampanyayı, esnek ve sürdürülebilir kentsel topluluklar yaratma vizyonuyla başlatmıştır. Bu kampanya, yerel yönetimleri, "Benim Kentim Hazırlanıyor" sloganı altında kentlerini olabildiğince esnek hale getirmeye davet etmiştir. Amacı yetkilileri BM-HABITAT'ın Sürdürülebilir Kentleşme ile ilgili Dünya Kentsel Kampanyası ile bağlantılı olarak, bir kontrol listesine ve projedeki yerel ağlarla çalışmaya ikna etmek ve 2005-2015 Hyogo Çerçeve Programı'na benzer stratejileri izlemektir. (Ulusların ve Toplulukların Afetlere Karşı Dayanıklılığının Geliştirilmesi (UNISDR, 2010). 2011 yılında “ Cooling the Public Realm Climate Resilient Urban Design "isimli makalede dirençli kentleri kentsel tasarım boyutu ile incelemiştir. (Raven, J., 2011).

2012 yılında ISET (Institute for Social and Environmental Transition-International) 5 ülkede Vietnam, Endonezya, Hindistan, Tayland ve Amerika'da 15 ilde iklim değişikliğinin bu kentler için oluşturacağı zorlukları belirlemek ve kentlerde iklim değişikliğine karşı dirençlilik kurmak için Climate Resilient Framework adında bir çerçeve tanımlamıştır (MacClune, K., \& Reed, S. O. , 2012). 2012 yılından başlayarak Arup şirketi Rockerfeller Foundation tarafından yaptırılan kentsel dirençlilik endeksi (City Resilience Index) 2015 yılına kadar güncellenerek devam etmiştir. $\mathrm{Bu}$ endeksten yararlanılarak kentsel dirençlilik çerçevesi oluşturulmuştur. Bu çerçevenin amaçları bir kentin dayanıklı olabilmesi için dört boyut, on iki hedef, elli iki gösterge ve yedi nitelik olarak belirlenmiştir. Bu dört boyut; sağlık ve refah, ekonomi ve toplum, altyapı ve çevre, liderlik ve strateji olarak sınıflandırılmıştır (ARUP,2014;ARUP,2015). 2014 yılında Asya Kalkınma Bankası Kentsel İklim Değişikliği Dirençliliği adında bir yayın yapmıştır. Bu yayında dirençliliği iklim değişikliği etkileri, hassas gruplar ve kentsel sistemler arasındaki ilişkiler olarak tanımlamaktadır (Asian Development Bank, 2014). Kentsel iklim değişikliği ve dirençlilik Amerika Birleşik Devletleri Çevre Koruma Ajansı tarafından bir şehrin kademeli iklim değişikliklerine veya aşırı iklim olaylarına maruz kalma ve hassasiyetini azaltma, aşırı iklim olaylarından kurtulma ve öğrenme yeteneği olarak tanımlanmıştır. Bu yetenek bir şehrin risk azaltma ve müdahale kapasitesinden gelir ve bir kent içindeki fiziksel, sosyal, kurumsal, çevresel ve yönetişim yapılarının korunmasını veya geliştirilmesi olarak tanımlanmaktadır (US,EPA, 2017).

Yukarıda bahsedilen çalışmalara göre literatürde ve ülkemizde kent planlama pratiğine dirençlilik kavramını bütünleştirecek yeni yöntemlere intiyaç bulunmaktadır.

\section{Yöntem}

Yapılan literatür ve YÖK ve WOS veritabanları taramasına göre dirençlilik alanında nicel çalışmaların eksikliği ortaya çıkmaktadır. Dirençlilik alanında yapılan çalışmaları inceleyen bir çalışmada (Witt ve Lil, 2018) araştırılan makalelerin \%55'inin nitel çalışmalardan oluştuğu ortaya konmuştur. Bu veriler ışığında konunun literatür çalışmaları ağırlıklı olması, bu alanda nicel yönde araştırma yapmaya intiyaç olduğunu göstermektedir.

Dirençlilik alanında yapılan endeks çalışmalarının öncülerinden Cutter tarafından hasar görebilirlik ve dirençlilik arasındaki ilişkiyi kurgulamak için bir model geliştirmiştir (Cutter ve diğ., 2008). Bu model dirençliliği, önceki koşullara, afetin ciddiyetine, tehlike olayları arasındaki zamana ve dış faktörlerin etkilerine bağlı dinamik bir süreç olarak sunmaktadır. DROP(Disaster Resilience of Place- Bir Mekanın Afet Dirençliliği) isimli bu modelde ekolojik, sosyal, ekonomik, kurumsal, altyapı ve toplumsal rekabet başlıklarında göstergeler belirlenmiş ancak model uygulamaya daha sonra geçmiştir (Cutter ve diğ., 2008)

2012 yılında Arup şirketi tarafından geliştirilen "City Resilience Index" kent planlama kapsamında yapılan ilk endeks çalışmalarındandır. Başlıklar halindeki bu endeks daha çok politika kararları düzeyindedir (Arup,2012). 2014 yılında yapılan bir çalışmada Amerika kentlerindeki afet dirençliliğinin ölçüldüğü bir endeks geliştirilmiştir (Cutter ve diğ., 2014). Bu 
endekste göstergeler sosyal dirençlilik, kurumsal dirençlilik, ekolojik dirençlilik, toplumsal sermaye ve ekonomik dirençlilik olarak sınıflandırılarak, göstergelerin normalizasyon 0 ve 1 arasında yapılmış, gösterge setleri Cronbach's Alfa modeli ile test edilmiştir. Bu modelin sonuç ürünü ise Amerika kentlerini dirençlilik puanına göre haritalandırılmasıdır (Cutter ve diğ., 2014).

Resilient Urban Planning: Major Principles and Criteria isimli çalışmada ise kentsel dirençliliği belirlemek için temel göstergeleri altyapı, güvenlik, çevre, ekonomi, kurumsal yapı, sosyal ve demografik yapı olarak sınıflandırmakta ve bunun alt bileşenlerini ise su, enerji, mekânsal konfigürasyon ve yer seçimi, ulaşım, yeşil altyapı, sığınma, yapılaşma koşulları ve tasarımı, bilgi teknolojileri, ekosistem, planlama, yönetim ve sağlık olarak tanımlanmıştır (Sharifi ve Yamagata, 2014). Kentsel dirençliliğin ölçümü adına 2016 yılında Suárez ve diğ.'nin çalışmasında dirençlilik endeksi formülü bulunmaktadır. Bu formül kentleri bir sistem olarak tanımlayarak sosyo- ekolojik dayanıkılık perspektifinden çeşitlilik (ekonomik çeşitlilik, arazi kullanımı çeşitliliği, gıda çeşitliliği, ve yerel gündem yirmi bir süreci), ve ekolojik ayak izi üzerinden kurulan bir formül ve endeksle kentlerin dirençliliğini ölçmektedir (Suárez, M.ve diğ., 2016).

Dirençliliği mutlak terimlerle ölçmek genellikle zor olduğundan, karşıllaştırmalı bir yaklaşım kullanmak ve sıralama belirlemek için göstergeler kullanılmaktadır. (Cutter ve diğ. 2008; Schneiderbauer ve Ehrlich 2006). Dirençlilik göstergeleriyle, hedeflenen sistemin veya analiz biriminin temel öğelerini belirlemeye yardımcı olmakta, bir karşılaştırma yapmakta, zayıf ve güçlü noktalar belirlenmekte, sistemi geliştirmek için planların nasıl yapılacağı ve fonların nereye yönlendirileceğini bilmek daha kolay olmaktadır (Cimellaro, G. P. 2016). Göstergeler konusunda daha önce bilimsel çalışmalarda önemi belirtilen, daha önce birden fazla alan çalışmasında uygulanmış ve evrensel olarak uygulanabilir olması, dirençlilikle açık bir ilişki göstermesi, ulusal veri kaynaklarından tutarlı verilerinin bulunması önemlidir. Göstergeler tehlike türü, zamansal ölçek, mekansal ölçek, bina tipi, gelişmişlik düzeyi, etki alanı, ölçüm yöntemi ile sınıflandırılmaktadır (Cimellaro, G. P. 2016).

Literatürde dirençliliğin sosyal, ekonomik, kurumsal, altyapısal, ekolojik ve topluluk unsurlarını içeren çok yönlü bir kavram olduğuna değinilmektedir. (Bruneau ve diğ. 2003; Cutter ve diğ., 2008) Göstergeler, alanlarına veya bakış açılarına göre de sınıflandırılabilir. Örneğin, ekolojik ve sosyal-ekolojik dirençlilik, psikolojik dirençlilik, kritik altyapısal dirençlilik veya örgütsel ve kurumsal dirençliliğe atıfta bulunan göstergeler bulunmaktadır (Birkmann ve diğ., 2012). Kentsel dirençlilik çalışmalarında göstergeler beş ana başlıkta toplanmaktadır. Bu başlıklar; fizik mekan göstergeleri, sosyal göstergeler, ekolojik göstergeler, yasal yönetsel yapı göstergeleri ve ekonomik göstergelerdir (Adger, 2000; Lin, 2006; Cutter ve diğ. 2007; Cutter ve diğ. 2008;Fernandez ve diğ.2013; ARUP, 2015). Bu göstergeler Tablo 2'de listelenmiştir.

Tablo 2. Literatürdeki Dirençlilik Göstergeleri (Kaynak: Galantini, 2018 ,sf.181-185)

\begin{tabular}{|l|l|}
\hline 1.FiZiK MEKAN GÖSTERGELERI & 2.EKOLOJiK GÖSTERGELER \\
\hline Fiziksel Altyapı & a.Su Kalitesi \\
\hline a.Fonksiyonlar & Okyanus asitlenmesi \\
\hline Konut & Tatlı su tüketimi \\
\hline Boş Kiralık Evlerin Yüzdesi & Okyanuslara azot ve fosfor girdileri \\
\hline Kent Merkezindeki Konutların Yüzdesi & Küresel hidrolojik döngü \\
\hline Geçici Evler (\%) & b.Hava Kalitesi \\
\hline Yeni Yapıların Ruhsat Oranı & Stratosferik ozon tabakası \\
\hline
\end{tabular}




\begin{tabular}{|c|c|}
\hline Yapı Yaşları & Atmosferik aerosol yüklemesi \\
\hline $\begin{array}{l}\text { Tiicari (dağıtım tesisleri; otel-konaklama; üretim tesisleri; ofis } \\
\text { hinaları) }\end{array}$ & c.Toprak Kalitesi \\
\hline $\begin{array}{l}\text { Kültürel (eğlence mekanları; müzeler; dini kurumlar; okullar; spor / } \\
\text { dinlonmo vorlori) }\end{array}$ & Arazi sistemi değişikliği \\
\hline b.Altyapı & $\%$ toprak erozyonu \\
\hline İletişim (internet; telefon; TV; radyo; posta) & \% geçirimsiz yüzey \\
\hline $\begin{array}{l}\text { Sağlık Hizmetleri(akut bakım; uzun süreli akut bakım; birinci } \\
\text { hacamak n ncikivatrik hakım. uzmanlk) }\end{array}$ & $\begin{array}{l}\text { Hidrik topraklı arazi yüzdesi } \\
\text { (cuwastırma) }\end{array}$ \\
\hline Gıda Temini & $\begin{array}{l}\text { Sulak alan kaybının yüzdesi (ekosistem } \\
\text { hizmotlori) }\end{array}$ \\
\hline (Elektrik; yakıt/gaz/enerji; atık; su) & Biyosfere azot ve fosfor girdileri \\
\hline Ulaşım; Hava; köprüler; otoyollar; demiryolları; deniz ) & d.Biyoçeşitlilik \\
\hline c. Arazi Kullanım & e.Biyokütle (bitki örtüsü) \\
\hline$\% 100$ yıllık taşkın alanında kalan yüzde & f.Diğer doğal kaynaklar \\
\hline \% Yeşil Alan / Bozulmamış Arazi & g. Kimyasalların dağılımı \\
\hline \% Ormanlık Alan Yüzdesi & h. İklim değişikliği \\
\hline$\%$ Erişilebilir Kentsel Alan & i. Çevresel değişkenlik / Tür zenginliği \\
\hline 3.SOSYAL GÖSTERGELER & 4.EKONOMIK GÖSTERGELER \\
\hline Nüfus ve Demografi & a. Finansal hizmetler \\
\hline a.Yayılma /Yoğunluk & Fİnansal kurumların varlık tabanı \\
\hline Kentsel & $\begin{array}{l}\text { Hesap bakiyelerini kontrol etme (kişisel } \\
\text { wo tiraril }\end{array}$ \\
\hline Uydukent & Tüketici fiyat endeksi \\
\hline Kırsal & Sigorta \\
\hline Orman & $\begin{array}{l}\text { Tek sektör istihdamı (\% birincil sektör + } \\
\text { turizm) }\end{array}$ \\
\hline Mülkiyet & Kadın işgücüne katılım (\%) \\
\hline Tadilatların Yeni Binalara Oranı & $\begin{array}{l}\text { İşletme büyüklüğü (\% büyük> } 100 \\
\text { colesn) }\end{array}$ \\
\hline b.Kompozisyon & Kredi sayısı ve ortalama miktarı \\
\hline Yaş & Banka ve kredi birliği sayısı \\
\hline Cinsiyet & $\begin{array}{l}\text { Tasarruf hesabı bakiyeleri (kişisel ve } \\
\text { tinori) }\end{array}$ \\
\hline Göçmenlik Statüsü & Borsa \\
\hline Irk /Etnisite & $\begin{array}{l}\text { Özel firmaların hakim olduğu bankacılık } \\
\text { coktörï }\end{array}$ \\
\hline Doğurganlık Oranı & $\begin{array}{l}\text { Piyasada rekabet edebilecek yabancı } \\
\text { hankalar }\end{array}$ \\
\hline Oturum izni için başvuran yabancı uyruklu vatandaşlar & Özel sektöre verilen kredi \\
\hline Fiziksel ve zihinsel engeli olmayan insan nüfusu oranı & $\begin{array}{l}\text { Faiz kontrolleri kredi piyasasına } \\
\text { müdahalo }\end{array}$ \\
\hline Büyük aileler & b. Sektör İstihdam-Hizmetler \\
\hline Tek ebeveynli aileler & Tarım \\
\hline c.Sosyo-Ekonomik Statü & İnşaat \\
\hline Eğitime Katılım & Eğitim ve sağlık hizmetleri \\
\hline Gelir & Finans, sigorta ve gayrimenkul \\
\hline Fakirlik & Bilgi, profesyonel iş, diğer \\
\hline Ev sahipliliği & Boş zaman ve misafirperverlik \\
\hline Konut Açığı & İmalat \\
\hline
\end{tabular}




\begin{tabular}{|c|c|}
\hline Meslekler & Şirket merkezi sayısı \\
\hline Yaşam Tarzı ve Topluluk Yetkinliği & Ulaşım ve kamu hizmetleri \\
\hline a.Kolektif eylem ve Karar verme & 250'den fazla çalışanı olan işyerlerinde \\
\hline Çatışma Çözümü & $\begin{array}{l}\text { Şirketlerin oluşumu ve kapatılması } \\
\text { aracındaki donas }\end{array}$ \\
\hline Organize Olabilme & Toptan ve Perakende \\
\hline Seçime Katılım Oranı & $\begin{array}{l}\text { İstihdam hizmetleri: dirençlilikler, } \\
\text { fırcatlar vorloctirmo }\end{array}$ \\
\hline 10,000 kişi başına düşen sivil toplum kuruluşu & c. Endüstriyel üretim \\
\hline 10,000 kişi başına düşen sosyal savunucu grup sayısı & Gıda temini \\
\hline b. Kamusal Fayda ve Güçlendirme & İmalat \\
\hline Felaket Esnasında Toplum Güveni & Şirket merkezi sayısı \\
\hline c. Yaşam Kalitesi & Ekonomik büyüme ve istikrar \\
\hline Sağlık Merkezlerindeki Kişi Başı Konsültasyonlar & d. Makroekonomik istikrar \\
\hline Fakirlik Yardımı Alanların Oranı & Mali açık / GSYH oranı \\
\hline İşsizlik Oranı & İşsizlik ve enflasyon oranlarının toplamı \\
\hline Kaynaklara Erişim & Dış borç / GSYIH oranı \\
\hline Sosyal / Kültürel Sermaye & e. Mikroekonomik piyasa verimliliği \\
\hline a.Çocuk ve Yaşlı Servisleri & 5.YASAL YÖNETSEL GÖSTERGELER \\
\hline b. Ticaret Merkezleri & Devlet Hizmetleri \\
\hline c.Topluluk katılımı / Sosyal ağlar ve sosyal yerleşiklik & a.İdari \\
\hline d. Kültürel Miras Servisler & Acil müdahale ve kurtarma \\
\hline e. Eğitim Servisleri & Tehlike azaltma planı kapsamındaki \\
\hline f. Kar amacı gütmeyen kuruluşlar & 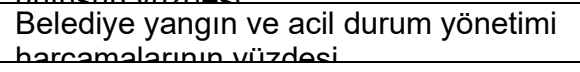 \\
\hline g. Yer Bağlantısı/Sığınak Güvenliği & Sağlık ve hijyen \\
\hline h. Sosyal Adalet / Cinsiyet Adaleti & Tehlike azaltma programlarına katılım \\
\hline i. Ulaşım Engeli (\% aracı olmayanlar) & Tehlike azaltma planları \\
\hline j. İletişim Engeli (\% telefonu olmayanlar) & İmar ve bina standartları \\
\hline k. Suç Oranı (kişi 10,000) & $\begin{array}{l}\text { b.Adli (Yargı } \\
\text { Ran̆ımaızlıăı/Tarafaıllı/Fikri }\end{array}$ \\
\hline
\end{tabular}

$\mathrm{Bu}$ çalışmada kullanılan göstergeler, Türk kentlerinde elde edilebilecek verilere, dirençlilik literatüründeki temel göstergelere göre kurgulanmıştır. Göstergeleri seçmek için, önce kentsel dirençlilik özelliklerini ve bunların dirençliliği nasıl etkilediğini endeksin temel değişkenleri olarak belirlenmiştir. Bu göstergeler ise üç ana başlık altında sınıflandırılmıştır. Bu başlıklar fizik mekan göstergeleri, çevre ve iklim göstergeleri ve sosyo-ekonomik yapı göstergeleridir. Bu çalışma kapsamında önerilen göstergeler Tablo 3 ' de listelenmiştir.

Tablo 3. Öneri Kentsel Dirençlilik Göstergeleri (Kaynak:Yazarlar tarafından hazırlanmıştır.)

\begin{tabular}{|l|l|}
\hline Fizik Mekan Göstergeleri & Kentsel Dirençliliğe Etkisi \\
\hline Planlama & \\
\hline Yapılı Alan & Negatif \\
\hline Yeşil Alan Oranı & Pozitif \\
\hline Arazi Kullanımı Konut/Iş̧yeri Oranı & Pozitif \\
\hline
\end{tabular}




\begin{tabular}{|c|c|}
\hline Afet Riski & \\
\hline Taşkın Sayısı & Negatif \\
\hline Jeolojik Olarak Sakıncalı Alanlar & Negatif \\
\hline Acil Durum İhbar Oranı & Negatif \\
\hline Taşkın Alanlarındaki Yapılaşma Oranı (100 Yıllık) & Negatif \\
\hline Çevre Ve İklim Göstergeleri & Kentsel Dirençliliğe Etkisi \\
\hline Çevresel Performans Değeri & Pozitif \\
\hline \multicolumn{2}{|l|}{ Meteorolojik Veriler } \\
\hline Aylık Maksimum Sıcaklık $\left({ }^{\circ} \mathrm{C}\right)$ & Negatif \\
\hline Maksimum Sıcaklığın $30^{\circ} \mathrm{C}$ Ve Üzerinde Olduğu Gün Sayısı & Negatif \\
\hline $\begin{array}{l}\text { Minimum Sicaklığın }-20^{\circ} \mathrm{C} \text { Ve Altında Olduğu Gün Sayısı } \\
\text { Ortalamacı }\end{array}$ & Negatif \\
\hline Aylık Maksimum Yağış (Mm=Kg $\left.\div \mathrm{M}^{2}\right)$ & Negatif \\
\hline Hava Kalitesi Değeri & Negatif \\
\hline \multicolumn{2}{|l|}{ Tüketim ve Atık } \\
\hline Su Tüketimi & Negatif \\
\hline Kati Atık Miktarı & Negatif \\
\hline Dönüşen Atık Miktarı & Pozitif \\
\hline Araç Sahipliliği Oranı & Negatif \\
\hline Sosyo-Ekonomik Yapı Göstergeleri & Kentsel Dirençliliğe Etkisi \\
\hline \multicolumn{2}{|l|}{ Demografik Yapı } \\
\hline Nüfus Yoğunluğu & Negatif \\
\hline 20 Yaşından Küçük veya 65 Yaşından Büyük Kişiler & Negatif \\
\hline Boşanmış Kişilerin Oranı & Negatif \\
\hline Yüksek Öğrenim Mezunu Kişilerin Sayısı & Negatif \\
\hline İnsani Gelişme Endeksi Sıralaması & Pozitif \\
\hline Yönetişim Ve Saydamlık Değeri & Pozitif \\
\hline \multicolumn{2}{|l|}{ Ekonomik Yapı } \\
\hline Yoksulluk Oranı & Negatif \\
\hline Yeşil Kart Sahibi Sayısı & Negatif \\
\hline Kiracı Hanehalkı Oranı & Negatif \\
\hline Satış Fiyatı & Pozitif \\
\hline Kira Fiyatı & Pozitif \\
\hline
\end{tabular}

Literatürde dirençlilik değerlendirmesi ve ölçümü için üç ana kategori tanımlanmıştır; bunlar endeksler, puan kartları, araçlar ve modellerdir. Endeksler, dirençliliğin seçilmiş bir özelliğini temsil eden ölçülebilir olanlardır ve farklı göstergeler bir endeks oluşturmak için birleştirilir. Endeksler birden çok göstergeyi tek bir değerde toplayarak gözlemleri veya ölçümleri özetleyen istatistiksel yaklaşımdır (Cimellaro, G. P. 2016).

Bu çalışmada kentlere özgü geliştirilecek olan endekste göstergeler oluşturmak için kompozit göstergeler yaklaşımı takip edilmiştir (Nardo ve diğ. , 2005). Bu metodoloji, çalışma kapsamında aşağıdaki adımlara uyarlanmıştır: 
- Uygun bir mekânsal analiz ölçeğinin seçilmesi,

- Dirençliliği sürdürmek için temel faktörleri tanımlamak,

- Göstergeleri seçmek,

- Verilerin normalizasyonu,

- Kentsel dirençlilik endeksine verilerin girilmesi,

- Sonuçların görselleştirilmesidir.

Göstergelerin seçimi ve sınıflandırılmasından sonra normalizasyonu 0 ve 1 arasında minimum maksimum yeniden ölçeklendirme formülü ile yapılmıştır. Bu ölçeklendirme, her bir değişkenin sıfır ile bir arasında özdeş bir aralığa ayrıştıııldığı bir yöntemdir (0 puan, belirli bir gösterge için en kötü sıralama ve 1 puan en iyisidir). Diğer tüm değerler minimum ve maksimum değerler arasında ölçeklenmiştir (Cutter ve diğ, 2010).

Göstergenin ham değerinin en yüksek değeri kentsel dirençlilik açısından pozitif ise ;

Gösterge $=($ Gerçek Değer- Minimum Değer) $/$ Maksimum Değer - MinimumDeğer

Göstergenin ham değerinin en yüksek değeri kentsel dirençlilik açısından negatif ise;

Gösterge=(Gerçek Değer-Maksimum Değer)/(Minimum Değer - Maksimum Değer olarak hesaplanmıştır.

Verilerin normalizasyonundan sonra endeks hesabında üç ana başlık altındaki göstergelerin normalize edilmiş değerlerinin (ağırlıkları da eşit olarak kabul edilerek) aritmetik ortalaması alınarak üç ana başlık için endeks değerleri belirlenmiştir. Aritmetik ortalama puanları her ölçüm bölgesi için bir alt endeks puanı oluşturmuş ve bu alt endeks puanları toplanarak nihai bir dirençlilik endeks puanı elde edilmiştir (Cutter ve diğ.,2010; Esty ve diğ., 2005).

Kentsel Dirençlilik Endeksi= Fizik Mekan Endeksi +Çevre ve İklim Endeksi+ SosyoEkonomik Yapı Endeksi

Bir kentsel envanterin, tematik haritaların ve sorguların oluşturulması, en hassas alanların belirlenmesine yardımcı olurken, "hizmet alanı" analizleri ve senaryoları, güçlendirme ve yeniden yerleştirme gibi etki azaltma önlemlerinin planlanmasına destek verir (Ercoşkun, 2012). Hesaplamalar sonucu çıkan bu değer seçilen kente dair analitik bir çerçeve sunarak hangi alanda eksiklerini tamamlaması gerektiğini ortaya koyarak plan kararlarına girdi sağlayacak, yatırım ve fonların doğru yönlendirilmesi için bir araç olacaktır.

\section{Sonuç}

Önerilen endeks ile kentlerin dirençlilik seviyelerini ölçmek için yeni bir yöntem ortaya konmuştur. Bu makalede değinilen dirençlilik alanında ve gelecekte üretilebilecek yeni çalışmalarda temel olabilecek yöntem açısından endeks verilmiş, veriler ve göstergelerin farklılaştırılarak özel amaçlara göre yeniden üretilebilir, uygulanabilir ve değiştirilebilir olmasına dikkat edilmiştir. Bu çalışma ile elde edilecek verilerle kentlerin hangi alanlarda dirençli hangi alanlarda kırılgan olduğu ortaya çıkartılacak, kent yöneticileri ve plancıları için bir rehber olacaktır. Çoklu göstergeler dirençliliğin bütüncül yapısına vurgu yaparken kenti bir bütün halinde analiz etmektedir. Bu endeksi plancılar bir kentin beklenmedik durumlar karşısındaki güçlü ve zayıf yönlerini Coğrafi Bilgi Sistemleriyle ortaya koyabilen bir matris olarak çalıştırıp özel proje alanlarını bulabilecek yeni bir araç olarak kullanabilirler. Bu endeks sonucunda dirençlilik değeri elde edilen yerleşmelerin zayıf ve güçlü yönlerinin ortaya 
konması, ihtiyaçlarını yeniden belirlemeye yol açacaktır. Bu endeksin sağladığı faydalardan birisi de iyileştirme intiyacı olan noktalara dair karşılaştırmalı genel bakış sağlamasıdır.

Endeksten çıkan sonuçlar kamu politikalarını tasarlamak ve kararları desteklemek için yararlı birer araçtır. Bu endeks politika kararları için geniş bir uygulama alanı oluşturmaktadır. İlerlemeyi ölçmek, intiyaçları değerlendirmek, müdahale veya azaltma süreçleri için bir kriter olarak; değişikliği izleme ve karşıllaştırmalar yapmak için fayda sağlamaktadır. Bu süreçte tüm kurumların verilerini aynı standartlarda üretmeleri, eşgüdümlü çalışmaları ve şeffaflık anlayışını benimsemeleri gerekmektedir. Kent planlamanın günümüz dünyasının değişen ve gelişen süreçlerine uyum sağlayabilmesinin yolu, yeni paradigmalara plan süreçlerinde yer vermek ve güncel sorunlara çözüm odaklı, akılcı ve objektif planlar geliştirebilmekten geçmektedir.

\section{Kaynaklar}

Adger, W.N. (2000). Social and ecological resilience: Are they related, Progress in Human Geography 24 (3), 347-364.

Adger, W.N. (2003). Building Resilience to Promote Sustainability, Newsletter of the International Human Dimensions

ARUP.(2014) . City Resilience Framework, The Rockefeller Foundation.

ARUP.(2015) . City Resilience Framework, The Rockefeller Foundation.

ARUP.(2015) . City Resilience Index , The Rockefeller Foundation.

Asian Cities Climate Change Resilience Network (ACCCRN): Responding to the Urban Climate Challenge. Eds. ISET, Boulder, Colorado, USA, 60 pp.

Asian Development Bank. (2014) Urban Climate Change Resilience.

Bahadur, Aditya, Ibrahim, Maggie, \& Tanner, Thomas. (2010). The resilience renaissance? Unpacking of resilience for tackling climate change and disasters (Strengthening Climate Resilience Discussion Papers No. 1). Brighton, UK.

Birkmann J, Chang Seng D, Abeling T, Huq N, Wolfertz J, Karanci N, 'Ikizer G, Kuhlicke C, Pelling M, Forrester J, Fordham M, Deeming H, Kruse S, Julich S (2012) Systematization of different concepts, quality criteria, and indicators. emBRACE project

Bosher, Lee \& Coaffee, Jon. (2008). Integrating Counter-Terrorist Resilience into Sustainability. Proceedings of The Ice - Urban Design and Planning. 161. 75-83. 10.1680/udap.2008.161.2.75.

Brown, Anna, Dayal, Ashvin, \& Rumbaitis Del Rio, Christina. (2012). From practice to theory: emerging lessons from Asia for building urban climate change resilience. Environment and Urbanization, 24(2), 531-556.

Bruneau, M., Chang, S.E., Eguchi, R.T., Lee, G.C., O'Rourke, T.D., Reinhorn, A.M., von Winterfeldt, D., (2003). .A framework to quantitatively assess and enhance the seismic resilience of communities. Earthq. Spectra 19 (4), 733 e752. 
Cimellaro, Gian Paolo (2016). [Geotechnical, Geological and Earthquake Engineering] Urban Resilience for Emergency Response and Recovery Volume 41 || Resilience Indicators. , 10.1007/978-3-319-30656-8(Chapter 3), 49-69. doi:10.1007/978-3-319-30656-8_3

Cutter, S.L., Johnson, L.A., Finch, C., Berry, M. (2007). The US hurricane coasts:increasingly vulnerable?,Environment 47 (7), 8-20.

Cutter, S. L., Barnes, L., Berry, M., Burton, C., Evans, E., Tate, E., \& Webb, J. (2008). A placebased model for understanding community resilience to natural disasters. Global Environmental Change, 18(4), 598-606. doi:10.1016/j.gloenvcha.2008.07.013

Cutter, Susan L.; Burton, Christopher G.; and Emrich, Christopher T. (2010) "Disaster

Resilience Indicators for Benchmarking Baseline Conditions," Journal of Homeland Security and Emergency Management: Vol. 7: Iss. 1, Article 51. DOI: 10.2202/1547-7355.1732

Cutter, S. L., Ash, K. D., \& Emrich, C. T. (2014). The geographies of community disaster resilience. Global Environmental Change, 29, 65-77. doi:10.1016/j.gloenvcha.2014.08.005

Chelleri, L., \& Olazabal, M. (2012).Multidisciplinary perspectives on urban resilience: A Workshop Report. (L. Chelleri \& M. Olazabal, Eds.) (pp. 1-76).

Coaffee, J. (2013). Rescaling and Responsibilising the Politics of Urban Resilience: From National Security to Local Place-Making. Politics, 33(4), 240-252.

Davoudi, S., \& Strange, I. (2009). Space and place in the twentieth century planning: An analytical framework and an historical review. In S. Davoudi \& I. Strange (Eds.), Conceptions of space and place in strategic spatial planning (pp. 7-42). London: Routledge.

Davoudi, S., Shaw, K., Haider, L. J., Quinlan, A. E., Peterson, G. D., Wilkinson, C., Fünfgeld, H., McEvoy, D., and Porter, L.,. (2012) Resilience: A Bridging Concept or a Dead End? "Reframing" Resilience: Challenges for Planning Theory and Practice Interacting Traps: Resilience Assessment of a Pasture Management System in Northern Afghanistan Urban Resilience: What Does it Mean in Planning Practice? Resilience as a Useful Concept for Climate ChangeAdaptation? The Politics of Resilience for Planning: A Cautionary Note. Planning Theory \& Practice 13(2): 299-333.

Eraydın, A. ,\& Taşan-Kok, T. (2013). Resilience Thinking in Urban Planning.In Ayda Eraydin \& T. Taşan-Kok (Eds.), (Vol. 106). Dordrecht: Springer Netherlands.

Ercoşkun ,Ö.Y. (2012) "A Paradigm Shift towards Urban Resilience", Green and Ecological Technologies for Urban Planning: Creating Smart Cities (ed.) Ö.Y. Ercoşkun, Hershey, PA: Information Science Publishing, s.1-16.

Esty, D.C., M. Levy, T. Srebotnjak and A. de Sherbinin. (2005). Environmental Sustainability Index: Benchmarking National Environmental Stewardship. New Haven: Yale Center for Environmental Law \& Policy

Fernandez N., Kim, S.J., Morsy, Z., Novak, V.M., Shiraishi, K. (2009). Improving Urban Resilience in Coastal Eco-Cities: System Integration, Coastal Eco-cities LRF Collegium 2013 Series I. 
Galantini,Z.D.(2018). Urban resilience as a policy paradigm for sustainable urban planning and urban development: The case of Istanbul. Doktora Tezi,İstanbul.

Godschalk, D. R. (2003). Urban hazard mitigation: Creating resilient cities. Natural Hazards Review, 4(3), 136-143.

Gupta, J., Termeer, C., Klostermann, J., Meijerink, S., van den Brink, M., Jong, P., et al. (2010). The adaptive capacity wheel: A method to assess the inherent characteristics of institutions to enable the adaptive capacity of society.

Lin, P.L. (2006). Urban resilience: Energetic principles and a systems ecology approach.

Linnenluecke, M., \& Griffiths, A. (2010). Beyond adaptation: Resilience for business in light of climate change and weather extremes. Business and Society, 49(3),477-511.

MacClune, K., \& Reed, S. O. (2012). Building urban resilience to climate change. Boulder, CO: Institute for Social and Environmental Transition-International.

Nardo, M., M. Saisana, A. Saltelli, S. Tarantola, A. Hoffman and E. Giovannini (2005) 'Handbook on constructing composite indicators: methodology and user guide', OECD Statistics Working Paper by, STD/DOC(2005) 3, see Publications and Documents at http:// www.oecd.org/ .

Opitz-Stapleton, S., Seraydarian, L., MacClune, K., Guibert G., \& Reed, S. (Eds.). (2009). Asian Cities Climate Change Resilience Network (ACCCRN): Responding to the urban climate challenge. Boulder, CO: Institute for Social and Environmental Transition-International (ISETInternational).

Raven, J. (2011). Cooling the Public Realm: Climate-Resilient Urban Design. Resilient Cities, 451-463. https://doi.org/10.1007/978-94-007-0785-6_45

Schneiderbauer, S., D. Ehrlich. (2006) "Social Levels and Hazard (in)- Dependence." Measuring Vulnerability to Natural Hazards: Towards Disaster Resilient Societiesedited by J. Birkmann. Tokyo, Japan: United Nations University Press, pp. 78-102.

Shaw,R.,(2009), City profile: climate and disaster resilience, Asia Regional Task Force On Urban Risk Reduction (RTF-URR), CITYNET (CITYNET), Kyoto University Graduate School Of Global Environmental Studies (KU GSGES), United Nations Office For Disaster Risk Reduction - Office In Japan (UNDRR OFFICE JAPAN), United Nations University (UNU)

Sharifi, A.,\& Yamagata, Y. (2014). Resilient Urban Planning: Major Principles and Criteria. Energy Procedia, 61, 1491-1495. doi: 10.1016/j.egypro.2014.12.154

Suárez, M., Gómez-Baggethun, E., Benayas, J., \& Tilbury, D. (2016). Towards an Urban Resilience Index: A Case Study in 50 Spanish Cities. Sustainability, 8(8), 774. doi: $10.3390 /$ su8080774

UNISDR (2009)Terminology on Disaster Risk Reduction. United Nations International Strategy for Disaster Risk Reduction, Geneva.

UNISDR ( 2012). How to make cities more resilient: A handbook for local government leaders. Geneva: United Nations. 
U.S. EPA, (2017) Evaluating Urban Resilience To Climate Change: A Multi-Sector Approach (Final Report). U.S. Environmental Protection Agency, Washington, D.C., EPA/600/R$16 / 365 F$.

Van den Brink, M., Termeer, C., \& Meijerink, S. (2011). Are Dutch water safety nstitutions prepared for climate change. Journal of Water and Climate Change, 2(4), 272-287.

Walker, H. B., Anderies, M., J, Kinzig, P.A., Ryan, P., (2006) Exploring Resilience in SocialEcological Systems through Comparative Studies and Theory Development: Introduction to the Special issue, Ecology and Society 11(1): 12.

Walker, H. B., Salt, D., (2006). Resilience thinking: sustaining ecosystems and people in a changing world, Island Press

Wardekker, J. A., de Jong, A., Knoop, J. M., \& van der Sluijs, J. P. (2010).Operationalising a resilience approach to adapting an urban delta to uncertain climate changes. Technological Forecasting and Social Change, 77(6), 987-998. White, I.

Witt, E., \& Lill, I. (2018).Methodologies of contemporary disaster resilience research. Procedia Engineering, 212, 970-977. doi: 10.1016/j.proeng.2018.01.12 